OPEN ACCESS

Edited by:

Hubert Vaudry,

University of Rouen, France

Reviewed by:

Catherine S. Hubbard,

Massachusetts General

Hospital/Harvard Medical

School, United States

Leo T. O. Lee,

University of Macau, China

*Correspondence:

Catherine Llorens-Cortes c.llorens-cortes@college-de-france.fr

tThese authors have contributed equally to this work and are both cofirst authors.

Specialty section:

This article was submitted to Neuroendocrine Science,

a section of the journal

Frontiers in Endocrinology

Received: 25 January 2017

Accepted: 16 May 2017

Published: 31 May 2017

Citation:

Flahault A, Couvineau P, Alvear-

Perez $R$, Iturrioz $X$ and Llorens-

Cortes C (2017) Role of the

Vasopressin/Apelin Balance and

Potential Use of Metabolically Stable

Apelin Analogs in Water Metabolism

Disorders.

Front. Endocrinol. 8:120.

doi: 10.3389/fendo.2017.00120

\section{Role of the Vasopressin/Apelin Balance and Potential Use of Metabolically Stable Apelin Analogs in Water Metabolism Disorders}

\author{
Adrien Flahault', Pierre Couvineau ${ }^{\dagger}$, Rodrigo Alvear-Perez, Xavier Iturrioz \\ and Catherine Llorens-Cortes*
}

Laboratory of Central Neuropeptides in the Regulation of Body Fluid Homeostasis and Cardiovascular Functions, Center for Interdisciplinary Research in Biology (CIRB), INSERM, U1050/CNRS, UMR 7241, College de France, Paris, France

Apelin, a (neuro)vasoactive peptide, plays a prominent role in controlling body fluid homeostasis and cardiovascular functions. In animal models, experimental data demonstrate that intracerebroventricular injection of apelin into lactating rats inhibits the phasic electrical activity of arginine vasopressin (AVP) neurons, reduces plasma AVP levels, and increases aqueous diuresis. In the kidney, apelin increases diuresis by increasing the renal microcirculation and by counteracting the antidiuretic effect of AVP at the tubular level. Moreover, after water deprivation or salt loading, in humans and in rodents, AVP and apelin are conversely regulated to facilitate systemic AVP release and to avoid additional water loss from the kidney. Furthermore, apelin and vasopressin secretion are significantly altered in various water metabolism disorders including hyponatremia and polyuria-polydipsia syndrome. Since the in vivo half-life of apelin is in the minute range, metabolically stable apelin analogs were developed. The efficacy of these lead compounds for decreasing AVP release and increasing both renal blood flow and diuresis, make them promising candidates for the treatment of water retention and/or hyponatremic disorders.

\section{Keywords: apelin, vasopressin, apelin receptor, metabolically stable apelin analogs, G protein-coupled receptor,} diuresis, osmolality, apelin water metabolism disorders

\section{DISCOVERY}

The apelin story began in 1993 with the cloning of the cDNA for the APJ receptor putative receptor protein related to the angiotensin II receptor type 1 (AT1) from a human genomic library (1). This receptor is a type A G protein-coupled receptor (GPCR) that shares $31 \%$ of amino acid sequence identity with the sequence of the human AT1 receptor. The human and the rat APJ receptors are 380 and 377 amino acids long, respectively. Studies have been performed to see if APJ receptor could bind angiotensin peptides due to its close homology with AT1 receptor. Binding experiments with angiotensin peptides were performed on Chinese Hamster Ovary (CHO) cells stably expressing the rat APJ receptor fused to enhanced Green Fluorescent Protein (EGFP). No specific binding for angiotensin II (Ang-II), angiotensin III (Ang-III), or angiotensin IV (Ang-IV) was observed in these cells. Moreover, stimulation of the rat APJ receptor by Ang-II or Ang-III at a concentration of $10^{-7} \mathrm{M}$ did not alter forskolin (FSK)-induced cAMP production, showing no activation of the rat APJ receptor by angiotensin peptides (2). These results showed that APJ receptor was not related to 
angiotensin peptides and remained an orphan GPCR for which the endogenous ligand had to be discovered.

In 1998, Tatemoto et al. isolated the endogenous ligand of the orphan APJ receptor from bovine stomach extracts. They used a Cytosensor microphysiometer to detect the metabolic activation of cells expressing the human APJ receptor through measurement of the extracellular acidification rate (3). This 36-amino acid peptide was called apelin for APJ Endogenous LIgaNd. Following the discovery of apelin, the APJ receptor was renamed the apelin receptor (ApelinR).

\section{GENE ENCODING/PROCESSING FOR APELIN AND THE ApelinR}

Apelin is generated from a 77-amino acid precursor, preproapelin (Figure 1). The gene encoding preproapelin is located on chromosome X at locus Xq25-26.1 in human, Xq35 in rat and XA3.2 in mouse (4). The human gene contains three exons, with the coding region spanning exons 1 and 2 . The $3^{\prime}$ untranslated region also spans two exons ( 2 and 3 ) (4). This may account for the presence of two different sizes of transcripts $(\approx 3$ and $\approx 3.6 \mathrm{~kb})$ in various tissues $(4,5)$. Alignment of preproapelin amino acid sequences from cattle, humans, rats, and mice shows strict conservation of the C-terminal 17 amino acids (amino acids 61-77 of preproapelin sequence), known as apelin-17 or K17F (Figure 1). In vivo, various molecular forms of apelin are present, differing only in length (either 36, 17, or 13 amino acids at the C-terminal part of the precursor) (6-10) (Figure 1).

The presence of pairs of basic residues within the cattle, human, rat, and mouse preproapelin sequences suggests that prohormone convertases could be responsible for the processing of the precursor to give birth to K17F and pE13F (pyroglutamyl form of apelin-13: amino acids $65-77$ of the preproapelin sequence). More recently, it has been shown in vitro that proprotein convertase subtilisin/kexin 3 (also named furin) may cleave proapelin (amino acids 23-77 of preproapelin sequence) directly into apelin 13 without generating longer isoforms (12). For apelin-36 (amino acids 42-77 of the preproapelin sequence) because of the absence of dibasic motifs upstream the apelin-36 cleavage site, the maturation mechanism remains to be defined. Apelin-36 predominates in rat lung, testis, uterus, and in bovine colostrums, whereas both apelin-36 and pE13F have been detected in the rat mammary gland $(6,8)$. In rat brain as well as in rat and human plasma, the predominant forms of apelin are $\mathrm{pE} 13 \mathrm{~F}$ and $\mathrm{K} 17 \mathrm{~F}$, whereas the concentration of apelin-36 is much lower $(9,10)$.

The gene encoding for the ApelinR is intronless in human and rodents and it is located on chromosome $11 \mathrm{q} 12$ in human (1), $2 \mathrm{E} 1$ in mouse, and $3 \mathrm{q} 24$ in rat $(2,5,6)$. The human and the rat ApelinRs are 380 and 377 amino acids long, respectively. The ApelinR amino acid sequence is conserved across species, with

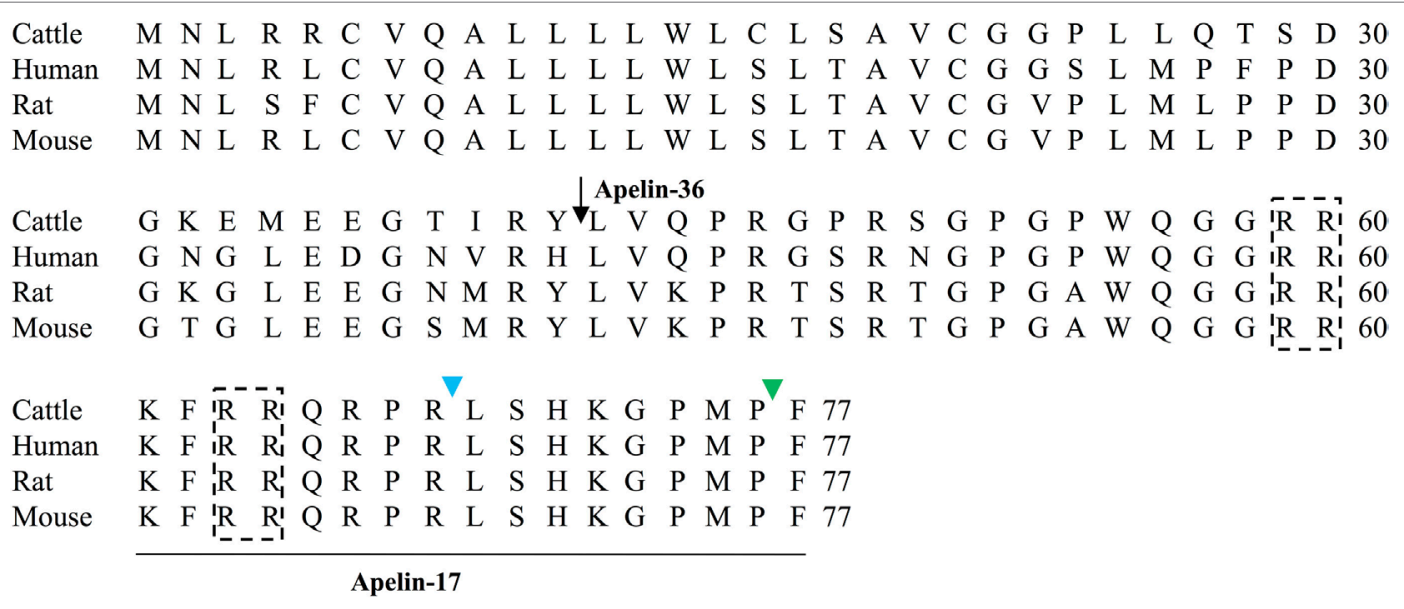

Molecular forms of apelin detected in vivo in rodents and humans

Apelin 36 L V Q P R G S R N G P G P W Q G G R R K F R R Q R P R L S H K G P M P F

Apelin 17 (K17F)

Pyroglutamyl form of apelin $13(\mathrm{pE} 13 \mathrm{~F})$

\author{
K F R R Q R P R L S H K G P M P F
}

pE R P R L S H K G P M P F

FIGURE 1 | Amino acid sequences of the apelin precursor, preproapelin, in cattle, humans, rats, and mice and the molecular forms of apelin detected in vivo. Alignment of preprapelin sequences in cattle, humans, rats, and mice. The arrow indicates the beginning of the sequence of apelin-36 and the apelin-17 (K17F) sequence, strictly conserved in mammals, is underlined. The black dashed boxes show the dibasic doublets that could be recognized by prohormone convertases, potentially involved in preproapelin maturation. The green arrow shows the cleavage site by ACE-2 (EC 3.4.17.23). The blue arrow shows the cleavage site by Neprilysin (EC 3.4.24.11). The various molecular forms of apelin detected in vivo in mammals: apelin-36, apelin-17, and the pyroglutamyl form of apelin-13. Figure adapted from Ref. (11) with permission from the copyright holders. 
more than $90 \%$ of homology between human and rodents, and up to $50 \%$ of homology with other non-mammalian species such as zebrafish or frog $(2,5,6,13)$. In contrast, Ang-II and apelin-13 do not show much homology; in fact, Ang-II (amino acid sequence: D-R-V-Y-I-H-P-F) only has in common with pE13F (pE-R-P-R-L-S-H-K-G-P-M-P-F) its two C-terminal amino acid residues $(\mathrm{P}-\mathrm{F})$. This explains why both peptides are cleaved by the carboxypeptidase, angiotensin-converting enzyme type- 2 (ACE-2, EC 3.4.17.23) (14, 15).

\section{METABOLISM OF APELIN PEPTIDES AND PHARMACOLOGICAL CHARACTERIZATION OF THE ApelinR}

ACE-2 removes the C-terminal phenylalanine of either apelin-36 $\mathrm{K} 17 \mathrm{~F}$ or pE13F $(14,15)$. Finally, it has been recently shown that neutral endopeptidase 24.11 or Neprilysin (EC 3.4.24.11) hydrolyzes the scissile peptide-bond $\mathrm{Arg}^{8}$-Leu' of K17F and $\mathrm{Arg}^{4}-\mathrm{Leu}^{5}$ of $\mathrm{pE} 13 \mathrm{~F}$ leading to two truncated inactive peptides (16).

Apelin peptides exhibit subnanomolar affinities for the ApelinR $(17,18)$. Alascan studies of pE13F showed that $\mathrm{Arg}^{2}, \mathrm{Arg}^{4}, \mathrm{Leu}^{5}$ of the RPRL motif of $\mathrm{pE} 13 \mathrm{~F}$ are key elements for ApelinR binding together with Ser ${ }^{6}, \mathrm{Lys}^{8}$, and $\mathrm{Met}^{11}$ but with a lesser extent (17). Later structure-function studies by molecular modeling and site-directed mutagenesis demonstrated that $\mathrm{Arg}^{2}, \mathrm{Arg}^{4}$, and Lys ${ }^{8}$ of $\mathrm{pE} 13 \mathrm{~F}$ interact with residues located at the top of the receptor, $\mathrm{Glu}^{172}$, Asp ${ }^{282}$, and $\mathrm{Asp}^{92}$, respectively (19).

Several studies have explored the signaling pathways activated by the apelin/ApelinR system. Apelin-36, K17F, apelin-13 (Q13F), and $\mathrm{pE} 13 \mathrm{~F}$ have been shown to have a similar potency (in the subnanomolar range) to inhibit FSK-induced cAMP production in $\mathrm{CHO}$ cells expressing the rat ApelinR and human embryonic kidney (HEK) cells expressing the human ApelinR (2, 7, 17, 20). Hosoya et al. (6) showed that Pertussis toxin was able to inhibit apelin-36 and $\mathrm{pE} 13 \mathrm{~F}$ responses demonstrating that ApelinR was coupled to $G \alpha_{\mathrm{i}}$. This was confirmed by Masri et al. who showed that ApelinR is preferentially coupled to $G \alpha_{i 1}$ and $G \alpha_{i 2}$ protein, which leads to the inhibition of adenylate cyclase and ERK1/2 phosphorylation but was not coupled to $\mathrm{G} \alpha_{\mathrm{i} 3}$ protein $(21,22)$.

Apelin-36, K17F, and $\mathrm{pE} 13 \mathrm{~F}$ have also been shown to increase $\left[\mathrm{Ca}^{2+}\right]_{\mathrm{i}}$ mobilization in Ntera 2 human teratocarcinoma (NT2N) cells, which differentiate into postmitotic neurons following retinoic acid stimulation and also in cells derived from basophils (RBL-2H3) or HEK 293 cells stably expressing human ApelinR $(17,23-25)$. However, the mechanisms underlying this production of calcium remain unknown. Moreover, Hus-Citharel et al. (26) showed that K17F decreases Ang-II-induced $\left[\mathrm{Ca}^{2+}\right]_{\mathrm{i}}$ mobilization in glomerular arterioles in a nitric oxide (NO)dependent manner. Interestingly, several studies have shown that the stimulation of ApelinR by apelin induces vasodilation and modulates vascular tone through NO production (22-24, $27,28)$. Furthermore, several kinases have been reported to be activated following apelin-induced ApelinR activation. Among these, the extracellular-regulated kinases (ERKs) are phosphorylated in $\mathrm{CHO}$ cells stably expressing the mouse ApelinR in a $\mathrm{G}_{\mathrm{i}}$-protein-dependent, protein kinase C (PKC)-dependent, and Ras-independent manner $(21,29)$. Apelin also stimulates phosphorylation of S6 ribosomal protein kinase (p70S6K) in human umbilical vein endothelial cells (HUVECs) and in $\mathrm{CHO}$ cells expressing the mouse ApelinR via two distinct signaling pathways-the phosphatidylinositol 3-kinase (PI3K)/Akt pathway and the ERK1/2 pathway $(29,30)$. Later on, D'Aniello et al. (31) have shown that apelin induces phosphorylation of p70S6 kinase in murine embryonic stem cells via an ERK1/2-dependent pathway.

Finally, as for most GPCRs, rat and human ApelinRs internalize upon the action of agonist ligands such as apelin-36, K17F, and $\mathrm{pE} 13 \mathrm{~F}(17,18,20,25,32)$. However, K17F is 30 times more potent in inducing rat ApelinR internalization when compared to pE13F (33). Deletion of the C-terminal Phe of K17F (K16P) or its substitution by an alanine (K17A) strongly decreases the ability of the peptide to trigger ApelinR internalization without effect on its affinity for the ApelinR or its ability to activate Goi-coupling $(18,20)$. This suggested that the C-terminal Phe of $\mathrm{K} 17 \mathrm{~F}$ or $\mathrm{pE} 13 \mathrm{~F}$ is a key residue to trigger ApelinR internalization (20). These results were supported by structure-function studies combining molecular modeling and site-directed mutagenesis of the ApelinR.

Docking of K17F into the three homology three-dimensional (3D) model of the ApelinR using the validated cholecystokinin receptor-1 3D model as a template revealed the presence at the bottom of the binding site of a hydrophobic cavity in which the C-terminal Phe of pE13F was embedded by $\operatorname{Trp}^{152}$ in TMIV and $\operatorname{Trp}^{259}$ and Phe ${ }^{255}$ in TMVI (18) (Figure 2). Using site-directed mutagenesis, $\mathrm{Phe}^{255}$ and $\operatorname{Trp}^{259}$ were shown to be crucial for

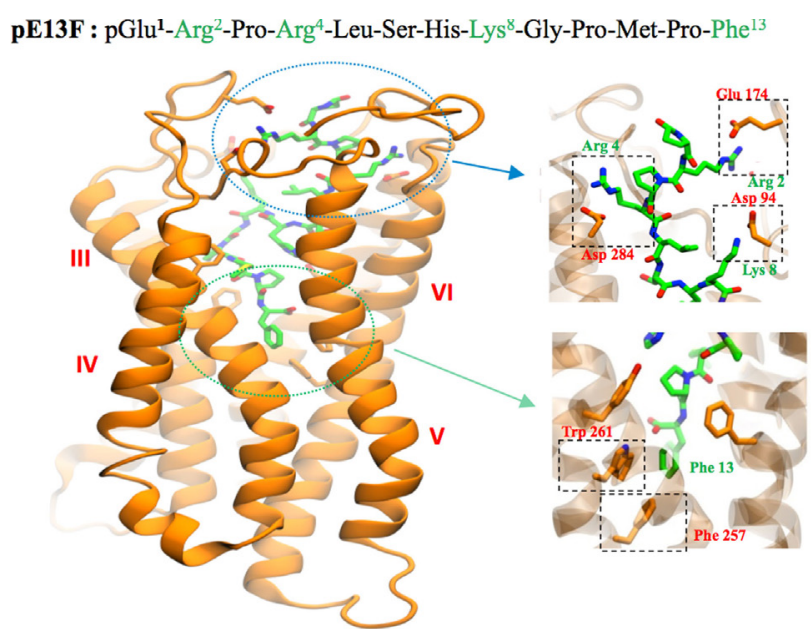

FIGURE 2 | Representation of the human ApelinR three-dimensional model complexed with $\mathrm{pE} 13 \mathrm{~F}$. The peptide backbone of the ApelinR is in orange while $\mathrm{pE} 13 \mathrm{~F}$ is in green. The blue dashed circle shows a detailed view of the binding site of $\mathrm{pE} 13 \mathrm{~F}$ with interactions (square dashed boxes) between basics residues of pE13F ( $\mathrm{Arg}^{2}, \mathrm{Arg}^{4}$, and $\mathrm{Lys}^{8}$, in green) and acidic residues of ApelinR (Asp ${ }^{94}$, Glu ${ }^{174}$, and Asp ${ }^{284}$, in orange). The green dashed circle shows a detailed view of the hydrophobic cavity within ApelinR in which the C-terminal Phe of pE13F (Phe ${ }^{13}$, in green) interacts with aromatic residues of ApelinR (Phe ${ }^{257}$ and $\operatorname{Trp}^{261}$, in orange). Figure adapted from Ref. (19) with permission from the copyright holders. 
ApelinR internalization without playing a role in apelin binding or $\mathrm{G}_{\mathrm{i}}$-protein coupling, by interacting with the C-terminal Phe of pE13F.

All these data indicate functional dissociation between ApelinR $\mathrm{G}_{\mathrm{i}}$-coupling and receptor internalization. This implies that the ApelinR exists in different active conformations depending on the ligand fitting into the binding site leading to the activation of different signaling pathways and subsequent different biological effects (18). Altogether, this suggests that ApelinR may exhibit "functional selectivity" or "biased signaling" by, on one hand, coupling with $\mathrm{G}$ protein and on the other hand by recruiting $\beta$-arrestins 1 and 2 (34). This hypothesis has been confirmed by Ceraudo et al. (34) who have shown that K17F activates ERK1/2 in a $\beta$-arrestin-dependent and $G_{i}$ protein-dependent manner whereas K16P only activates $G_{i}$ protein. This functional selectivity of apelin peptides indicates that the $\beta$-arrestin-dependent ERK1/2 activation and not the Gi-dependent signaling may participate in K17F-induced BP decrease. Indeed, when pE13A and $\mathrm{K} 16 \mathrm{P}$ are injected intravenously in rats, they lost their capacity to decrease arterial blood pressure (BP) when compared with the corresponding natural peptides $\mathrm{pE} 13 \mathrm{~F}$ and $\mathrm{K} 17 \mathrm{~F}(20,35)$.

The characterization of the internalization pattern of the ApelinR induced by apelin-36 or pE13F demonstrates that the internalized ApelinR/pE13F complex is rapidly recycled to the cell surface via a Rab4 pathway. The internalized ApelinR/apelin-36 complex is targeted to lysosomes through a Rab7 pathway. Both of these pathways are linked to $\beta$-arrestin 1 association with differences in spatio-temporal association (36). These differences are in agreement with studies showing that apelin-36 leads to a strong and sustained desensitization whereas the $\mathrm{pE} 13 \mathrm{~F}$-induced desensitization is transient (21). Therefore, subtle differences exist between the apelin isoforms regarding their pharmacological properties, which may influence their physiological actions.

As numerous GPCRs, ApelinR may also form heterodimers in vitro with other GPCRs. ApelinR has been shown to dimerize with AT1, leading to an inhibition of Ang-II signaling by apelin (37-39). ApelinR may also heterodimerize with $\kappa$-opioid receptor, leading to an increase in cell proliferation through an increase of PKC and a decrease of protein kinase A (PKA) activity (40). In HUVEC cells, ApelinR has been shown to heterodimerize with bradykinin type 1 receptor, leading to an increase in cell proliferation and in phosphorylation of eNOs through a $\mathrm{G}_{\mathrm{q}}$ protein-dependent PKC signaling pathway (41).

\section{DEVELOPMENT OF METABOLICALLY STABLE APELIN ANALOGS}

The in vivo transient effects of apelin fragments suggested that endogenous apelin peptides have a short half-life. In addition, Gerbier et al. (33) showed that K17F and pE13F have a half-life in mouse plasma of 4.6 and $7.2 \mathrm{~min}$, respectively, and Murza et al. (42) showed that $\mathrm{pE} 13 \mathrm{~F}$ has a 14 min half-life in rat plasma. Regarding apelin-36, Japp et al. (43) suggested from experiments conducted in healthy human subjects that the half-life of apelin 36 is lower than $5 \mathrm{~min}$. This short half-life could be attributed to the action of metabolic enzymes including exo- and endo-peptidases.
The short in vivo half-life of apelin encouraged the development of metabolically stable apelin analogs for potential therapeutic applications.

Numerous technologies, such as PEGylation (44, 45), palmytoylation (46) conjugation to albumin, N-terminal acetylation (33), C-terminal amidation (47), use of unnatural amino acids $(15,33,42,48)$, or main chain modifications (cyclization) (49-51) have now been set up to increase the in vivo plasma half-life of peptides (52). Table 1 summarizes the pharmacological characteristics of the main metabolically stable apelin analogs described in this section.

Most studies that aim to develop apelin analogs have focused on pE13F $(15,42,46,48,50,51,53)$ or apelin-36 $(44,45)$; however, K17F, which had an affinity 10 times higher than that of pE13F for human ApelinR, was 10 times more efficient at inducing internalization of rat ApelinR and also decreased arterial BP more strongly than did pE13F (20).

Given these findings, metabolically stable K17F analogs were recently developed $(15,33)$. For this purpose, each amino acid of the sequence of K17F, which includes that of $\mathrm{pE} 13 \mathrm{~F}$, was replaced with its $\mathrm{D}$-isomer or with an unnatural amino acid. It was found in agreement with previous alanine scanning $\mathrm{pE} 13 \mathrm{~F}$ studies $(17,54)$ that replacement of the $\mathrm{Arg}^{2}, \mathrm{Arg}^{4}, \mathrm{Ser}^{6}, \mathrm{Lys}^{8}$, and $\mathrm{Gly}^{9}$ residues of $\mathrm{pE} 13 \mathrm{~F}$ with corresponding $\mathrm{D}$-amino acids greatly decreased the ability of these compounds to bind to ApelinR or to inhibit FSK-induced cAMP production. Thus, combination of acetylation of $\mathrm{Lys}^{1}$ and the introduction of D-Arg ${ }^{3}$ and D-Gln ${ }^{5}$, $\mathrm{D}-\mathrm{Leu}^{9}, \mathrm{Aib}^{11}, \mathrm{D}-\mathrm{Ala}^{13}, \mathrm{Nle}^{15}$, and $4 \mathrm{Br}-\mathrm{Phe}^{17}$ in $\mathrm{K} 17 \mathrm{~F}$, generating P92, which had an affinity of $0.09 \mathrm{nM}$ for the ApelinR, similar to that of $\mathrm{K} 17 \mathrm{~F}(0.06 \mathrm{nM})$. On the other hand, an original strategy for improving the protection of endogenous peptides against enzymatic degradation on the basis of the introduction of a fluorocarbon chain (FC) directly into the $\mathrm{N}$-terminal part of $\mathrm{K} 17 \mathrm{~F}$ was used to generate LIT01-196. The presence of the FC on the apelin peptide had no impact on the affinity of LIT01-196 for ApelinR $\left(K_{\mathrm{i}}=0.08 \mathrm{nM}\right)$, or on its solubility in water $(>10 \mathrm{mM})$.

Altogether these chemical modifications allowed to an extend the plasma half-lives of P92 by a factor of 6-11 and that of LIT01196 by a factor of $>100$ relative to that of K17F. LIT01-196 displayed remarkable resistance to degradation by plasma enzymes, as $>90 \%$ of the peptide remained unchanged after $24 \mathrm{~h}$ of incubation at $37^{\circ} \mathrm{C}$. FC acylation of an endogenous peptide therefore seems to be an efficient way to extend its half-life in plasma.

P92 and LIT01-196 displayed full agonist activity for cAMP production, ERK1/2 phosphorylation (nanomolar range), induction of ApelinR internalization (subnanomolar range), and $\beta$-arrestin recruitment (33).

\section{PHYSIOLOGICAL EFFECTS OF APELIN}

\section{Distribution of Apelin and Its Receptor Brain}

RT-PCR $(8,17)$, in situ hybridization (55) and Northern blot $(4,5)$ studies have shown that mRNAs coding for preproapelin and the ApelinR were distributed heterogeneously in different brain structures. The distribution of apelinergic neurons in the 


\begin{tabular}{|c|c|c|c|c|}
\hline & Reference & Affinity $\left(K_{\mathrm{i}}, \mathrm{nM}\right)$ & $\begin{array}{l}\text { cAMP production inhibition } \\
\qquad\left(\mathrm{IC}_{50}, \mathrm{nM}\right)\end{array}$ & $\begin{array}{c}\text { Half-life in } \\
\text { plasma }^{\text {(min) }}\end{array}$ \\
\hline \multicolumn{5}{|l|}{ Apelin-13 } \\
\hline$p E-R-P-R-L-S-H-K-G-P-M-P-F(p E 13 F)$ & (33) & $0.56 \pm 0.07$ & $1.68 \pm 0.47$ & 7.2 \\
\hline E-R-P-R-L-S-H-K-G-P-Nle-P-2Nal & (48) & $1.2 \pm 0.1$ & $20.5 \pm 6$ & $<120$ \\
\hline E-R-P-R-L-S-H-K-G-P-Nle-P-4Br(F) & $(48)$ & $1.2 \pm 0.1$ & $12.4 \pm 3$ & $<60$ \\
\hline E-R-P-R-L-S-H-K-G-P-Nle-Aib-F & (48) & $1.8 \pm 0.2$ & $20.9 \pm 7$ & $<60$ \\
\hline pE-R-P-R-L-S-H-K-G-P-Nle-P-Bpa & $(42,53)$ & $0.38 \pm 0.04$ & $0.04 \pm 0.02$ & 55 \\
\hline pE-R-P-R-L-S-H-K-G-P-Nle-P-Y(O)Bn & $(42,53)$ & $0.016 \pm 0.002$ & $0.35 \pm 0.09$ & 66 \\
\hline pE-R-P-R-L-S-H-K-G-P-Nle-P-F(L- $\alpha \mathrm{CH} 3)$ & $(42,53)$ & $0.34 \pm 0.02$ & $0.07 \pm 0.02$ & $>120$ \\
\hline Cyclo(1-6)C-R-P-R-L-C-H-K-G-P-M-P & $(50)$ & 300 & $2.7 \pm 0.8$ & ND \\
\hline Palmitoyl-E-R-P-R-L-S-H-K-G-P-Nle-Aib-F & $(46)$ & ND & $21.6 \pm 4.5$ & 1,740 \\
\hline Cyclo(7-11)pE-R-P-R-L-S-AllyG-K-G-P-AllyG-P-Y(O)Bn & (51) & $1.7 \pm 0.25$ & $35 \pm 11$ & ND \\
\hline Ac-E-R-P-R-(D)L-S-Aib-K-(D)A-P-Nle-P-4Br(F) & (33) & $2.11 \pm 0.40$ & $2.22 \pm 1.00$ & 86 \\
\hline pE-R-P-R-L-S-H-K-G-P-Nle-Aib-Br(F) & $(15)$ & ND & ND & $>60$ \\
\hline \multicolumn{5}{|l|}{ Apelin-17 } \\
\hline$K-F-R-R-Q-R-P-R-L-S-H-K-G-P-M-P-F(K 17 F)$ & (33) & $0.06 \pm 0.01$ & $0.30 \pm 0.10$ & 4.6 \\
\hline Ac-K-F-(D)R-R-(D)Q-R-P-R-(D)L-S-Aib-K-(D)A-P-Nle-P-4Br(F) (P92) & (33) & $0.09 \pm 0.02$ & $0.56 \pm 0.32$ & 24 \\
\hline CF3((CF2)7(CH2)2C(O)-K-F-R-R-Q-R-P-R-L-S-H-K-G-P-M-P-F (LIT01-196) & (33) & $0.08 \pm 0.01$ & $1.71 \pm 0.28$ & $>1,440$ \\
\hline K-F-R-R-Q-R-P-R-L-S-H-K-G-P-Nle-Aib-Br(F) & (15) & ND & ND & 30 \\
\hline \multicolumn{5}{|l|}{ Apelin-36 } \\
\hline$L-V-Q-P-R-G-S-R-N-G-P-G-P-W-Q-G-G-R-$ & $(6,7,43)$ & $4.8 \pm 0.24$ & 0.52 & $<5^{\mathrm{b}}$ \\
\hline \multicolumn{5}{|l|}{$R-K-F-R-R-Q-R-P-R-L-S-H-K-G-P-M-P-F$} \\
\hline 40 kDa-PEG-Apelin-36 & $(44)$ & 0.3 & 1.5 & ND \\
\hline Apelin-36-[L28C(30 kDa-PEG)] & $(45)$ & ND & $3,050 \pm 2,100$ & ND \\
\hline
\end{tabular}

aEx vivo plasma half-life (unless otherwise specified).

${ }^{b}$ In vivo plasma half-life.

ND, not determined; G, glycine; AllyG, allylglycine; P, proline; A, alanine; V, valine; L, leucine; I, isoleucine; M, methionine; C, cysteine; F, phenylalanine; Y, tyrosine; W, tryptophan; H, histidine; K, lysine; R, arginine; Q, glutamine; N, asparagine; E, glutamic acid; D, aspartic acid; S, serine; T, threonine; Aib, aminoisobutyric acid; Y(O)Bn, tyrosine(O)benryl; Bpa, benzoillphenyl; Nle, norleucine; 2Nal, naphtalen-2-yl-propanoic acid; $4 \mathrm{Br}(F)$, 4-bromo-phenylalanine; PEG, polyethyleneglycol.

In bold and italic characters: native apelin peptides.

In bold characters: name of the analog as it is referred in the article.

adult rat brain has been studied using a polyclonal antibody with a high affinity and selectivity for K17F, which also recognizes pE13F and apelin-36 $(9,32,56)$. Apelin-immunoreactive (IR) neuronal cell bodies are abundant in brain structures that are involved in neuroendocrine control, food intake, drinking behavior, and regulation of $\mathrm{BP}$, such as the hypothalamus and the medulla oblongata. They are particularly present in the supraoptic nucleus (SON), the magnocellular part of the paraventricular nucleus (PVN), the arcuate nucleus, the nucleus ambiguous, and the lateral reticular nucleus (56). Conversely, apelin-IR nerve fibers and nerve endings are more widely distributed in the brain: a high density was observed in the inner layer of the median eminence and in the posterior pituitary $(32,57)$. This suggests that, similarly to magnocellular vasopressinergic and oxytocinergic neurons, the apelinergic neurons of the PVN and the SON project into the posterior pituitary. This hypothesis was verified using double immunofluorescence staining showing that apelin was colocalized with arginine vasopressin (AVP) $(9,58)$ and oxytocin $(57,59)$ in magnocellular neurons. Apelin-IR cell bodies and fibers were also identified along the lamina terminalis, which is located in a region along the third ventricle and contains the subfornical organ (SFO), the organum vasculosum of the lamina terminalis (OVLT), and the median preoptic nucleus, which are involved in the control of drinking behavior $(60,61)$. The SFO and the OVLT, which contain fenestrated capillaries and no blood-brain barrier, constitute a link between peripheral events such as severe dehydration or hypovolemia and adaptive brain responses such as water intake or AVP release. Figure 3A shows the neuroanatomical distribution of apelin-IR cell bodies and nerve fibers on a parasagittal section of adult colchicinetreated rat brain.

The ApelinR is also widely distributed in the rat central nervous system Figure 3B $(2,4,5)$. ApelinR mRNA has been identified using in situ hybridization in the piriform and the entorinal cortices, the hippocampus and in the pars compacta of the substantia nigra, the dorsal raphe nucleus and the locus coeruleus, which contain the monoaminergic neuronal cell bodies. The level of expression of ApelinR mRNA is high in the hypothalamic nuclei, including the SON and the PVN, the arcuate nucleus, the pineal gland, and the anterior and intermediate lobes of the pituitary gland (2). Moreover, double labeling studies combining in situ hybridization and immunohistochemistry have shown that, in the SON and PVN, mRNAs coding for the ApelinR $(32,62)$ as well as AVP receptors type $1 \mathrm{a}(\mathrm{V} 1 \mathrm{a})$ and $1 \mathrm{~b}(\mathrm{~V} 1 \mathrm{~b})$, but not type 2 (V2R) (63), are coexpressed by magnocellular AVP neurons. This strongly strengthens the existence of an interaction between AVP and apelin.

\section{Kidney}

RT-PCR studies have shown that mRNA coding for preproapelin, as well as for ApelinR, is expressed in rat and human kidney $(5,17)$. Apelin-like immunoreactivity was also detected in human 

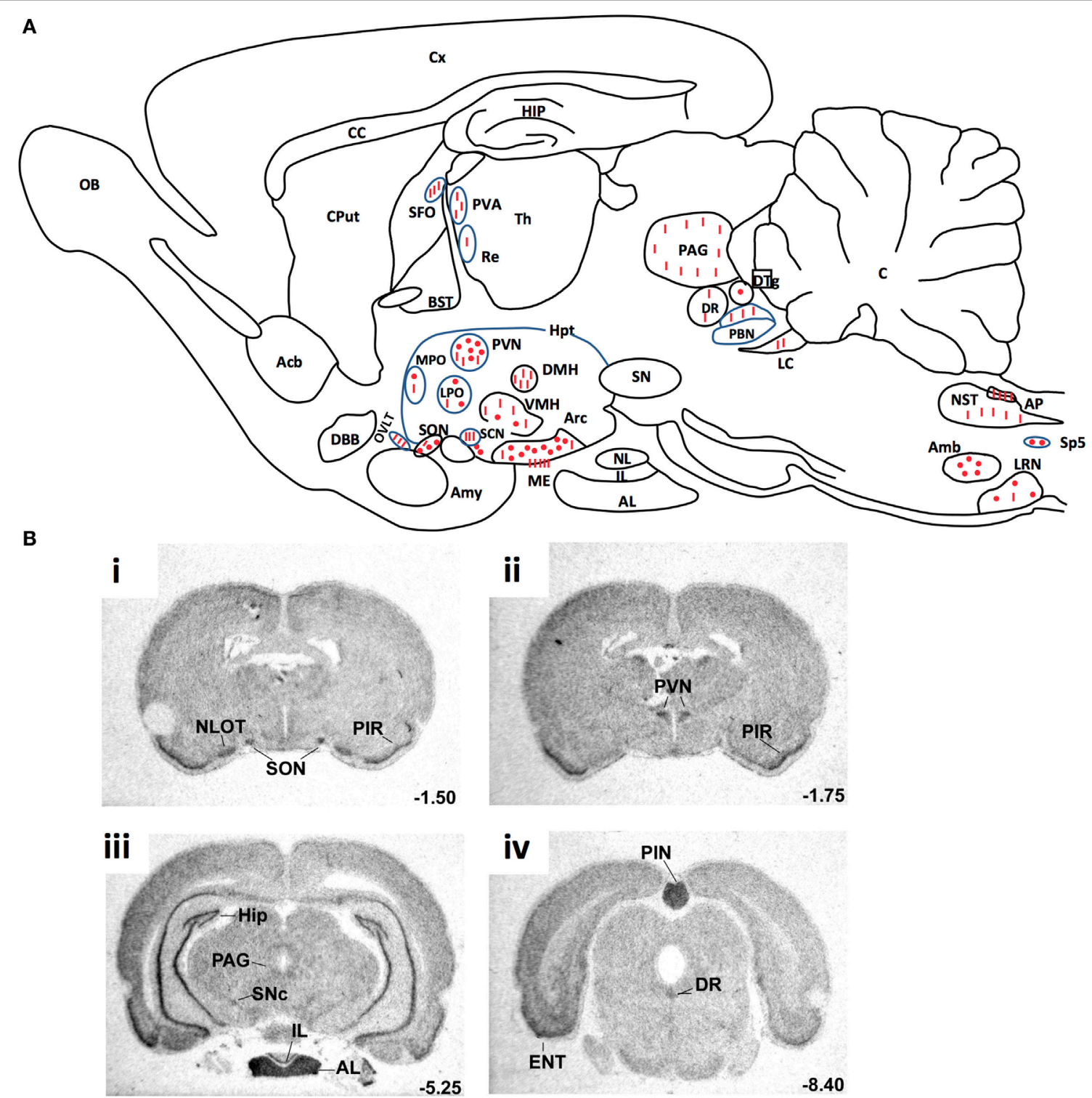

FIGURE 3 | (A) Neuroanatomical distribution of apelin-IR cell bodies and nerve fibers on a parasagittal section of adult colchicine-treated rat brain. Apelin-IR cell bodies and nerve fibers are shown as dots and lines, respectively. Figure adapted from Ref. (56) with permission from the copyright holders. (B). Distribution of the rat ApelinR mRNA expression in the adult rat brain. The figures were scanned directly from the X-ray film. Shown are representative frontal sections at anteriorities determined from the bregma indicated in the lower right corner. i-iv were hybridized with the antisense ApelinR cRNA probe. Scale bar: 2 mm. Figure adapted from Ref. (2) with permission from the copyright holders. Abbreviations: Acb, nucleus accumbens; Amb, nucleus ambiguus; Amy, amygdala; AL, anterior lobe of the pituitary gland; AP, area postrema; Arc, arcuate nucleus of the hypothalamus; BST, bed nucleus of the stria terminalis; C, cerebellum; CC, corpus callosum; Cput, caudate putamen; Cx, cerebral cortex; DBB, diagonal band of Broca; DMH, dorsomedial nucleus of the hypothalamus; DR, dorsal raphe nucleus; DTg, dorsal tegmental nucleus; ENT, entorhinal cortex; HIP, hippocampus; Hpt, hypothalamus; IL, intermediate lobe of the pituitary; LC, locus coeruleus; LPO, lateral preoptic area; LRN, lateral reticular nucleus; ME, median eminence; MPO, medial preoptic nucleus; NL, neural lobe of the pituitary; NLOT, nucleus of the lateral olfactory tract; NST, nucleus of the solitary tract; OB, olfactory bulb; OVLT, vascular organ of the lamina terminalis; PAG, periaqueductal gray; PBN, parabrachial nucleus; PIN, pineal gland; PIR, piriform cortex; PVA, paraventricular thalamic nucleus; PVN, paraventricular nucleus of the hypothalamus; Re, reuniens thalamic nucleus; SCN, suprachiasmatic nucleus; SFO, subfornical organ; SN, substantia nigra; SNc, pars compacta of the substantia nigra; SON, supraoptic nucleus; Sp5, spinal trigeminal nucleus; S, septum; Th, thalamus; VMH, ventromedial nucleus of the hypothalamus.

endothelial cells obtained from small intrarenal vessels (64). In situ hybridization studies in the rat kidney showed that ApelinR mRNA was expressed in the endothelial cells and vascular smooth muscle cells of the rat glomerular arterioles. ApelinR mRNA has also been detected and in all renal zones (26), most abundantly in the inner stripe (IS) and the outer stripe (OS) of the outer medulla (OM) (26). Furthermore, a high ApelinR mRNA expression was found in glomeruli and moderate in all the nephron segments including the collecting duct (CD) (26) where the V2R are also expressed (65). 


\section{Maintenance of Water Balance by Apelin and Vasopressin through Central and Renal Effects \\ Central Effects of Apelin on AVP Neuronal Activity, AVP Release and Diuresis}

Arginine vasopressin, also known as anti-diuretic hormone, is a peptide that has antidiuretic and vasocontricting effects. It is synthesized and released by hypothalamic magnocellular AVP neurons in the blood circulation from the fenestrated capillaries of the posterior pituitary in response to variations in plasma osmolality and volemia $(66,67)$ or under the influence of neurohormones including natriuretic and angiotensin peptides $(68,69)$. The colocalization of AVP, apelin, V1, and ApelinR in magnocellular neurons suggests an interaction between apelin and AVP. This raises the possibility of an effect of apelin in response to osmotic or volemic stimuli. It has been hypothesized that independently from the feedback control exerted by AVP on its own release $(69,70)$, apelin may regulate AVP release. This hypothesis was checked in two animal models. First, the lactating rat, which exhibits an increase in the activity of magnocellular AVP neurons, leading to an increase in AVP synthesis and release in order to preserve water of the organism for maximal milk production $(71,72)$. In this model, the intracerebroventricular (i.c.v.) administration of apelin (K17F) (9) induces an inhibition of the phasic electrical activity of AVP neurons, reduces the release of AVP in the bloodstream and increases diuresis, without changes in sodium and potassium excretion (Figure 4). Second, in mice deprived of water for $24 / 48 \mathrm{~h}$, a condition known to increase AVP neuron activity and systemic AVP release $(73,74)$, i.c.v. administration of K17F induced a significant decrease in systemic AVP release. These results suggest that apelin is probably released from the SON and PVN AVP cell bodies and inhibits AVP neuron activity and release through a direct action on the apelin autoreceptors expressed by AVP/apelin-containing neurons. This mechanism probably involves apelin acting as a natural inhibitor of the antidiuretic effect of AVP.

\section{Effects of Apelin and Vasopressin on the} Maintenance of Water Balance at the Kidney Level In addition to a central action, the aquaretic effect of apelin probably involves a renal action because of the expression of ApelinR

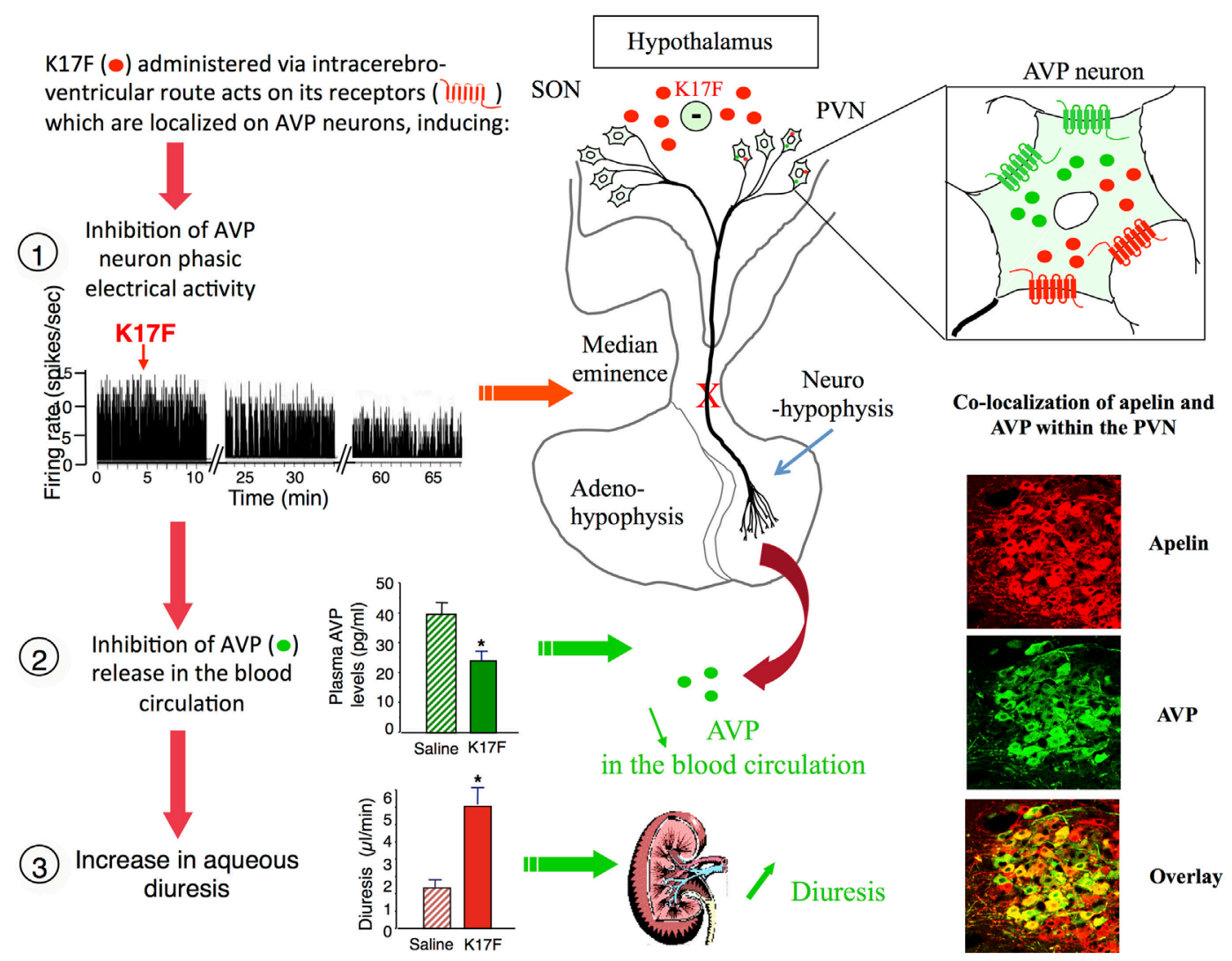

FIGURE 4 | Central action of apelin on vasopressinergic neuron activity. Apelin and its receptor (ApelinR, red) are colocalized in magnocellular vasopressinergic neurons of the supraoptic nucleus and paraventricular nucleus (PVN), with arginine vasopressin (AVP) and vasopressin receptor type 1 (green). In lactating rats, i.c.V. injection of apelin 17 (K17F) inhibits the phasic electrical activity of AVP magnocellular neurons, leading to a decrease in AVP release in the bloodstream and an increase in aqueous diuresis. On the right of the figure are represented confocal images illustrating the distribution of apelin and AVP IR cell bodies within the rat PVN. A high colocalization of apelin (red) and AVP (green) has been detected in PVN magnocellular neurons. Dually labeled cells stand out in yellow when images are merged. Figure adapted from Ref. $(11,58)$ with permission from the copyright holders. 
and preproapelin, as well as apelin immunoreactivity in the kidney $(5,17,64)$. ApelinR mRNA has been detected in all renal zones, most abundantly in the IS of the OM (26). A high level of expression was also detected in the glomeruli and a moderate expression was observed in all nephron segments, especially in CD that express V2R In agreement with the presence of ApelinR mRNA in juxtamedullary efferent (EA) and afferent (AA) arterioles, application on glomerular arterioles precontracted by Ang-II of K17F, induced NO-dependent vasorelaxation by inhibiting the Ang-II induced rise in intracellular calcium mobilization (26). The apelin-dependent vasorelaxation observed in muscular EA, which gives rise to vasa recta, therefore strongly supports a key role of apelin in the control of renal medullary circulation (26).

On the other hand, it is well known that AVP by stimulating $\mathrm{V} 2 \mathrm{R}$ in $\mathrm{CD}$ induces an increase in cAMP production and activates PKA which phosphorylates aquaporin type 2 (AQP2). This results in the insertion of AQP2 at the apical membrane of the principal cells of the $\operatorname{CD}(75,76)$, leading to water reabsorption, decreasing diuresis, and plasma osmolality. The expression of ApelinR mRNA in the CD suggests that apelin could act as an aquaretic peptide through a direct action on this nephron segment. In agreement with this hypothesis, application of K17F on medullary CD inhibits CAMP production induced by dDAVP (a specific and selective $\mathrm{V} 2 \mathrm{R}$ agonist) and decreased the dDAVP-induced calcium influx in CD cells (77). Finally, intravenous injection of K17F in increasing doses in lactating rats increases diuresis in a dose-dependent manner concomitantly with a significant decrease in urine osmolality and a decrease in AQP2 insertion at the apical membrane of CD (77), showing that K17F-induced diuresis is linked to a direct action of apelin on CD. Similarly, in other studies $(78,79)$, acute or chronic intravenous treatment with apelin-13 potently increased diuresis in male Sprague-Dawley rats.

Thus, the aquaretic effect of apelin is not only due to a central effect by inhibiting AVP release in the blood circulation but also to a direct action of apelin at the kidney level by increasing renal blood flow and counteracting the antidiuretic effect of AVP occurring via $\mathrm{V} 2 \mathrm{R}$ in $\mathrm{CD}$.

These results also show that apelin and AVP have opposite effects on the $\mathrm{CD}$ and contribute to control plasma osmolality by regulating the reabsorption of water by the kidney (Figure 5).

Recent studies have underlined the role of apelin in controlling fluid homeostasis. As previously reported, water deprivation significantly decreases urine volume and increases urine osmolality in wild-type mice, whereas mice deficient for the ApelinR (Apelin $\mathrm{R}^{-1-}$ ) were unable to concentrate their urine to the same extent $(80,81)$. This lack of effect is likely not due to an inability of these mice to increase plasma AVP levels since similar increases in plasma AVP levels are seen in wild-type and ApelinR ${ }^{-/-}$mice following water deprivation, suggesting the presence of an intact central vasopressinergic system in ApelinR ${ }^{-1-}$ mice. These observations have therefore led the authors to suggest that since the defect in water metabolism observed in ApelinR ${ }^{-/-}$mice is not due to altered AVP neurosecretory function, it could be due to a defect in urine concentration at the kidney level. These results contrast with other studies published showing an aquaretic role of apelin in rodents. A possible explanation for this discrepancy is that in knock-out models, the total absence of ApelinRs during fetal and adult life could elicit compensatory mechanisms, leading to this opposite effects on urine output observed following an exogenous administration of apelin via i.c.v (9) and i.v. $(26,33$, 77-79) routes. In addition, apelin gene expression in the brain has been also reported as a hydration-sensitive gene expression (82).

\section{Effects of the Metabolically Stable Apelin Analogs, P92 and LIT01-196, at the Central and Kidney Levels}

Central administration of P92 and LIT01-196 decreases dehydration-induced systemic AVP release in a dose-dependent manner and they are 6 and 160 times, respectively, more effective than K17F (33). These data suggest that P92 and LIT01-196, like $\mathrm{K} 17 \mathrm{~F}$, rapidly reach the hypothalamic structures that are involved in AVP release from the posterior pituitary into the bloodstream after i.c.v. injection. They subsequently act on ApelinR expressed by AVP neurons to inhibit their phasic electrical activity, thereby preventing AVP release into the bloodstream. Furthermore, intravenous administration of P92 and LIT01-196 in anesthetized rats, at a dose in the $\mathrm{nmol} / \mathrm{kg}$ range, potently increased urine output. In parallel, P92 and LIT01-196-induced vasorelaxation of rat glomerular arterioles, respectively, precontracted with Ang-II (33). This strongly suggests that these apelin analogs can act like K17F to increase medullary blood flow (26). Thus, by decreasing AVP release into the bloodstream and by increasing both renal blood flow and urine output, these new compounds should also have an aquaretic effect similar to that previously reported for $\mathrm{K} 17 \mathrm{~F}$ in lactating rats $(9,26)$. ApelinR agonists of this type would be particularly useful for the treatment of water retention and hyponatremia, making it possible to avoid the excessive sodium loss that is frequently reported in patients receiving thiazidic or loop diuretics.

\section{Opposite Regulation of Vasopressin and Apelin following Water Deprivation \\ In Rodents}

The colocalization and opposing actions of apelin and AVP on diuresis raise questions concerning how they are regulated to maintain body fluid homeostasis. To this end, the effect of water deprivation on the neuronal content and release of apelin and AVP were studied in rodents, and the effects of different states of hydration on plasma AVP and apelin levels were studied in human volunteers.

Following water deprivation in rodents, AVP is released into the blood circulation faster than it is synthesized, causing a depletion of AVP magnocellular neuronal stores (83). In parallel, water deprivation decreases plasma apelin levels and induces an increase in hypothalamic apelin neuronal content, especially in the PVN and SON AVP magnocellular neurons $(9,58)$. Following water deprivation, apelin therefore accumulates within AVP neurons rather than being released. This increase in neuronal apelin concentration observed in dehydrated rats is markedly reduced by the i.c.v. administration of a selective V1 receptor antagonist whereas the i.c.v. infusion of AVP has similar effects to dehydration on neuronal apelin content (58).

The apelin response to dehydration is therefore opposite to that of $\operatorname{AVP}(9,83)$. These results imply that AVP and apelin are 


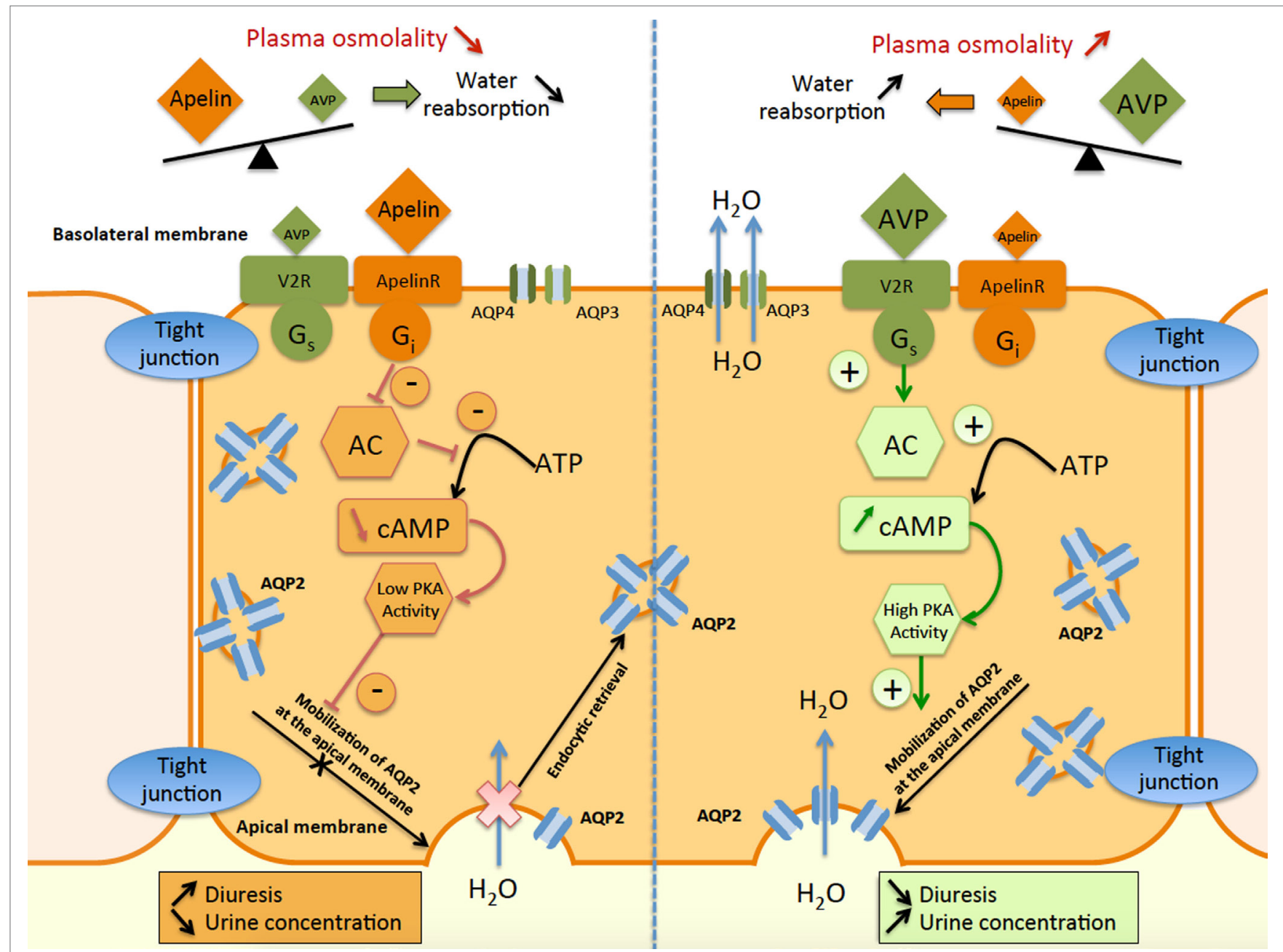

FIGURE 5 | Schematic representation of apelin and vasopressin signaling pathways in principal cells of the collecting duct (CD). In the principal cells of the CD, arginine vasopressin binds to the V2-receptor (V2R), which stimulates adenylate cyclase (AC) via $\mathrm{G}_{\mathrm{s}}$ coupling and increases cAMP production. This results in an increase in protein kinase $\mathrm{A}(\mathrm{PKA})$ activity, inducing the insertion of aquaporin type 2 (AQP2) at the apical membrane. Water reabsorption $\left(\mathrm{H}_{2} \mathrm{O}\right)$ is allowed by $\mathrm{AQP} 2$ at the apical membrane and AQP3 and AQP4 at the basolateral membrane, leading simultaneously to a decrease in diuresis and an increase in urine concentration. In contrast, apelin binds to the ApelinR, inhibiting AC through $G_{i}$ coupling and decreasing CAMP production and PKA activity. This results in a decrease in AQP2 insertion at the apical membrane, leading to a decrease in water reabsorption and consequently in an increase in diuresis and a decrease in urine concentration.

released separately by the AVP magnocellular neurons in which they are produced. In agreement with this hypothesis, double immunolabeling confocal microscopy studies show that a large proportion of apelin immunoreactivity colocalizes with AVP in magnocellular neurons in the SON and the PVN (Figure 4), although each peptide is found within distinct subcellular compartments $(9,58)$.

These in vivo animal studies show that the cross-regulation of apelin and AVP following osmotic stimuli has a physiologic purpose, allowing the maintenance of the organism water balance by preventing water excretion by the kidney after water deprivation.

\section{In Humans}

Such cross-regulation of apelin and AVP following osmotic stimuli has also been studied in humans. The relationship between osmolality, apelin, and AVP in the plasma was investigated in healthy men (10) following $2 \mathrm{~h}$ of hypertonic saline infusion to increase plasma osmolality or $30 \mathrm{~min}$ of oral water loading to decrease plasma osmolality.

Increased plasma osmolality simultaneously raised plasma AVP levels and decreased plasma apelin levels. Conversely, decreased plasma osmolality reduced plasma AVP levels and rapidly increased plasma apelin levels (10). These observations are consistent with plasma osmolality being a major physiologic regulator of plasma apelin levels in humans. Furthermore, the inverse relationship between the regulation of apelin and AVP is consistent with the findings in animal models following water deprivation. This strongly suggests that, like AVP, apelin helps to maintain body fluid homeostasis in humans and rodents. 


\section{Effects of Aging on the Cross Regulation of Apelin and Vasopressin}

It has been shown in humans that elderlies have a higher risk of dehydration, due to lower levels of water intake and excessive water loss $(84,85)$. Both apelin and AVP contribute to maintain water homeostasis, and their regulation has therefore been investigated during aging.

Aging has been associated with an increase in the size of the magnocellular AVP neuron cell bodies (86), nucleoli (87), and Golgi apparatus $(88,89)$ in aged humans, and numerous studies have shown higher plasma AVP levels in aged rodents (90-93). In a recent study conducted in adult (3 weeks of age) or aged (22 weeks of age) male Wistar rats (94), intracellular AVP mRNA levels in the SON were lower in aged rats whereas intracellular apelin mRNA levels in the SON were higher. The authors then investigated the effect of dehydration on plasma AVP and apelin levels and showed an impaired response to dehydration of aged rats on both plasma AVP levels, which did not increase significantly after dehydration in aged rats, as well as on plasma apelin levels, which did not decrease significantly after dehydration as previously shown in adult rats (9).

Thus, there may be an absence of additional up- and downregulation of AVP and apelin in response to a sustained osmotic challenge, as the neuronal system may already be functioning at maximal capacity. Microglial inflammation and overproduction of interleukins have been proposed to contribute to the observed modifications of central apelin and AVP responses to osmotic changes in aged rats. The age-dependent impairment of the AVP/apelin response after an osmotic challenge could explain the poor tolerance of older patients to dehydration, although these results are yet to be confirmed in clinical studies involving elderlies.

\section{Apelin and Vasopressin Balance in Different Pathologies Hyponatremia}

Hyponatremia, defined by a plasma sodium concentration below $135 \mathrm{mmol} / \mathrm{l}$, is a common metabolic disorder associated with an increased risk in mortality in hospitalized patients. It is usually secondary to free water retention rather than insufficient sodium intake. Various conditions have been associated with hyponatremia, including drug adverse events (diuretics, antidepressants), chronic heart failure (CHF), chronic liver disease, and the syndrome of inappropriate antidiuretic hormone secretion (SIADH). Copeptin corresponds to the C-terminal part of the AVP precursor and is composed of 77 amino acids. Copeptin is released mole to mole with AVP from the posterior pituitary in the blood circulation and plasma copeptin levels are used as a surrogate marker for AVP release in humans $(95,96)$. Copeptin measurement alone has proven useful in hyponatremic disorders to differentiate patients with primary polydipsia (PP), who have low copeptin plasma concentration and low urine osmolality, from other causes of hyponatremia such as SIADH, but do not allow to differentiate SIADH from other causes hyponatremic disorders such as diuretic-induced hyponatremia, hypovolemic hyponatremia, and hypervolemic hyponatremia (97).

\section{Syndrome of Inappropriate Antidiuretic Hormone (SIADH)}

In SIADH, abnormal AVP osmoregulation is the primary defect (98). A recent study showed that copeptin was useful to characterize five different subtypes of SIADH, according to plasma copeptin concentration response to hypertonic saline infusion (99). Since an opposite relationship is observed in healthy subjects between plasma apelin and AVP concentrations following osmotic stimuli, the apelin response to the AVP osmoregulation defect in SIADH was investigated (100). Expected ranges of plasma apelin, copeptin levels, and plasma to copeptin ratio for a given plasma sodium concentration were established in healthy subjects. In patients with SIADH, the sex- and age-adjusted apelin and copeptin levels were higher than in healthy subjects, by 26 and $75 \%$, respectively. However, during an acute osmotic challenge, plasma copeptin levels were higher and plasma apelin levels lower than expected from plasma sodium and the plasma apelin to copeptin ratio decreased exponentially with natremia. Apelin to copeptin ratios as a function of natremia were outside the $95 \%$ predicted physiological limits for $86 \%$ of SIADH patients.

This study showed that apelin levels and apelin to copeptin ratios were inappropriate to natremia in SIADH patients, suggesting that the increase in plasma apelin secretion cannot compensate for the higher levels of vasopressin release and may contribute to the corresponding water metabolism defect.

\section{Heart Failure}

In $\mathrm{CHF}$, the decrease in cardiac output and in effective circulating volume results in activation of baroreceptors. These activate the sympathetic nervous system, the renin-angiotensin-aldosterone system, and the release of AVP in the bloodstream. The increase in plasma AVP concentration leads to water reabsorption by the kidney (101). Mild to moderate hyponatremia is present in approximately $10 \%$ of CHF patients (102). Hyponatremic patients with advanced CHF often exhibit abnormally elevated AVP plasma levels (103), and hyponatremia has been associated with reduced survival and increased complications in CHF (104). Similarly to SIADH, the apelin to copeptin balance was investigated in hyponatremic CHF patients (100). In this study, plasma copeptin levels were increased by $190 \%$ compared to healthy subjects in hyponatremic patients. Plasma apelin levels were also slightly increased (by 25\%). The plasma apelin to copeptin ratio was lower in CHF patients than in controls, suggesting that the mild increase in apelin secretion could not counteract the major increase in AVP secretion, leading to abnormal water metabolism and hyponatremia (100).

\section{Polyuria-Polydipsia}

In response to an increase in plasma osmolality, i.e. in case of dehydration or of hypertonic saline infusion, it has been shown both in humans and in animals that AVP secretion is increased and apelin secretion is decreased, allowing the reabsorption of water by the kidney. Thirst is also stimulated by the increase 
in plasma osmolality. In human pathology, an increase in both fluid intake (polydipsia) and diuresis (hypotonic urine output) is characteristic of the polyuria-polydipsia syndrome (PPS). Three entities are comprised in the PPS: central (complete or partial), diabetes insipidus (DI), nephrogenic (complete or partial) DI, and PP. Central DI (CDI) is secondary to complete or partial brain AVP deficiency mirrored by low plasma copeptin levels. In most cases, thirst perception is intact, resulting in polyuria, polydipsia. Severe hyperosmolality only occurs in case of fluid deprivation. Nephrogenic DI (NDI) is secondary to renal insensitivity to AVP and can be acquired or hereditary, due to mutations of the V2R or of AQP2. PP is not due to a deficiency or resistance of AVP but rather results from an excessive fluid intake over an extended period of time, in the absence of plasma osmolality regulation disorder. PP results from an abnormal thirst mechanism or a psychiatric disorder (105). Plasma copeptin measurement before and after water deprivation can be used to establish the differential diagnosis between each entity with good sensitivity and specificity (106). In order to determine if, similarly to what was observed in hypoosmolar disorders, apelin secretion was also impaired in PPS, the plasma apelin and copeptin levels were measured in PPS patients with complete CDI, complete NDI and PP(107). In patients with NDI, plasma copeptin levels were higher than those measured in healthy volunteers and plasma apelin levels were also increased by $61 \%$ compared to control values, probably in an effort of the apelin/AVP system to reestablish the water balance mediated by the two hormones. However, since in NDI AVP is unable to exert its antidiuretic effect at the kidney level, it is likely that only apelin exerts its deleterious effect, which results in polyuria.

In CDI, plasma copeptin levels were decreased by $52 \%$ compared to healthy volunteers whereas plasma apelin levels were only decreased by $18 \%$. However, the plasma apelin to copeptin ratio was higher in CDI patients than in healthy volunteers. Possibly, the decrease in plasma apelin levels of patients with CDI is insufficient as compared to the decrease of AVP/copeptin to reestablish a balance between the antidiuretic effect of AVP and the diuretic effect of apelin, resulting in polyuria.

Patients with PP had normal plasma copeptin and slightly but significantly lower plasma apelin levels compared to healthy volunteers. However, the apelin to copeptin ratio was similar to that measured in healthy volunteers. This suggests that the normal apelin to copeptin ratio attests for balanced water homeostasis, whereas plasma apelin to copeptin ratio in CDI or NDI is increased or decreased compared to healthy volunteers, reflecting a disturbed water homeostasis.

Another interesting explanation is that apelin itself might also be involved directly in the pathogenesis of PP. Indeed, the decrease in plasma apelin levels in PP patients could account for altered drinking behavior (leading to an inadequate fluid intake in these patients) since i.c.v. injection of apelin into water deprived rats decreases drinking behavior (32). Further studies need to be conducted in order to determine if the use of the apelin to copeptin ratio could be a useful diagnosis tool in hyperosmolar disorders.

\section{CONCLUSION AND PERSPECTIVES}

The discovery of apelin as the endogenous ligand of the ApelinR is an important step in basic research and has clinical implications. In animal models, experimental data demonstrate that central injection of apelin into lactating rats inhibits the phasic electrical activity of AVP neurons, reduces plasma AVP levels, and increases aqueous diuresis. In the kidney, apelin increases diuresis by increasing renal blood flow and by counteracting the antidiuretic effect of AVP at the tubular level. Moreover, following water deprivation or salt loading, in humans and in rodents, AVP and apelin are conversely regulated to facilitate systemic AVP release and to avoid additional water loss at the kidney level. These data show that, together with AVP, apelin play a crucial role in the maintenance of body fluid homeostasis. In addition, in SIADH or CHF patients with hyponatremia, the apelin to copeptin balance is altered contributing to the water metabolism defect. The administration of apelin agonists in these patients could induce aqueous diuresis and therefore increase water excretion, reversing hyponatremia.

To date, there are no published preclinical or clinical studies utilizing ApelinR agonists/analogs in pathological animal models or patients with water metabolism disorders. The development of metabolically stable apelin analogs that exert longer-lasting and more potent effects than the endogenous peptide on aqueous diuresis and which additionally could only target the $\mathrm{G}_{\mathrm{i}}$ signaling pathway like the endogenous apelin fragment K16P (biased agonist), represent promising candidates for the treatment of water retention/hyponatremic disorders.

\section{AUTHOR NOTES}

All appropriate permissions have been obtained from the copyright holders of Figures 1-4 that were adapted and reproduced for this manuscript.

\section{AUTHOR CONTRIBUTIONS}

All authors listed have made substantial, direct, and intellectual contribution to the work and approved it for publication.

\section{FUNDING}

These studies were supported by INSERM (through financial support for Proof of Concept, CoPoC, INSERM Transfert, in particular), the Centre National de la Recherche Scientifique, the Université de Strasbourg, the Collège de France, and the Agence Nationale pour la Recherche "Physique et Chimie du Vivant 2009." AF was supported by a Poste d'Accueil INSERM grant. 


\section{REFERENCES}

1. O’Dowd BF, Heiber M, Chan A, Heng HH, Tsui LC, Kennedy JL, et al. A human gene that shows identity with the gene encoding the angiotensin receptor is located on chromosome 11. Gene (1993) 136:355-60. doi:10.1016/0378-1119(93)90495-O

2. De Mota N, Lenkei Z, Llorens-Cortès C. Cloning, pharmacological characterization and brain distribution of the rat apelin receptor. Neuroendocrinology (2000) 72:400-7. doi:10.1159/000054609

3. Tatemoto K, Hosoya M, Habata Y, Fujii R, Kakegawa T, Zou MX, et al. Isolation and characterization of a novel endogenous peptide ligand for the human APJ receptor. Biochem Biophys Res Commun (1998) 251:471-6. doi:10.1006/bbrc.1998.9489

4. Lee DK, Cheng R, Nguyen T, Fan T, Kariyawasam AP, Liu Y, et al. Characterization of apelin, the ligand for the APJ receptor. J Neurochem (2000) 74:34-41. doi:10.1046/j.1471-4159.2000.0740034.x

5. O'Carroll AM, Selby TL, Palkovits M, Lolait SJ. Distribution of mRNA encoding B78/apj, the rat homologue of the human APJ receptor, and its endogenous ligand apelin in brain and peripheral tissues. Biochim Biophys Acta (2000) 1492:72-80. doi:10.1016/S0167-4781(00)00072-5

6. Hosoya M, Kawamata Y, Fukusumi S, Fujii R, Habata Y, Hinuma S, et al. Molecular and functional characteristics of APJ. Tissue distribution of mRNA and interaction with the endogenous ligand apelin. JBiol Chem (2000) 275:21061-7. doi:10.1074/jbc.M908417199

7. Habata Y, Fujii R, Hosoya M, Fukusumi S, Kawamata Y, Hinuma S, et al. Apelin, the natural ligand of the orphan receptor APJ, is abundantly secreted in the colostrum. Biochim Biophys Acta (1999) 1452:25-35. doi:10.1016/ S0167-4889(99)00114-7

8. Kawamata Y, Habata Y, Fukusumi S, Hosoya M, Fujii R, Hinuma S, et al. Molecular properties of apelin: tissue distribution and receptor binding. Biochim Biophys Acta (2001) 1538:162-71. doi:10.1016/S0167-4889(00) 00143-9

9. De Mota N, Reaux-Le Goazigo A, El Messari S, Chartrel N, Roesch D, Dujardin C, et al. Apelin, a potent diuretic neuropeptide counteracting vasopressin actions through inhibition of vasopressin neuron activity and vasopressin release. Proc Natl Acad Sci U S A (2004) 101:10464-9. doi:10.1073/ pnas.0403518101

10. Azizi M, Iturrioz X, Blanchard A, Peyrard S, De Mota N, Chartrel N, et al. Reciprocal regulation of plasma apelin and vasopressin by osmotic stimuli. J Am Soc Nephrol (2008) 19:1015-24. doi:10.1681/ASN.2007070816

11. Galanth C, Hus-Citharel A, Li B, Llorens-Cortès C. Apelin in the control of body fluid homeostasis and cardiovascular functions. Curr Pharm Des (2012) 18:789-98. doi:10.2174/138161212799277770

12. Shin K, Pandey A, Liu X-Q, Anini Y, Rainey JK. Preferential apelin-13 production by the proprotein convertase PCSK3 is implicated in obesity. FEBS Open Bio (2013) 3:328-33. doi:10.1016/j.fob.2013.08.001

13. Devic E, Rizzoti K, Bodin S, Knibiehler B, Audigier Y. Amino acid sequence and embryonic expression of msr/apj, the mouse homolog of Xenopus X-msr and human APJ. Mech Dev (1999) 84:199-203. doi:10.1016/S0925-4773 (99)00081-7

14. Vickers C, Hales P, Kaushik V, Dick L, Gavin J, Tang J, et al. Hydrolysis of biological peptides by human angiotensin-converting enzyme-related carboxypeptidase. J Biol Chem (2002) 277:14838-43. doi:10.1074/jbc.M200581200

15. Wang W, McKinnie SMK, Farhan M, Paul M, McDonald T, McLean B, et al. Angiotensin-converting enzyme 2 metabolizes and partially inactivates Pyr-apelin-13 and apelin-17: physiological effects in the cardiovascular system. Hypertension (2016) 68:365-77. doi:10.1161/HYPERTENSIONAHA. 115.06892

16. McKinnie SMK, Fischer C, Tran KMH, Wang W, Mosquera F, Oudit GY, et al. The metalloprotease neprilysin degrades and inactivates apelin peptides. Chembiochem (2016) 17:1495-8. doi:10.1002/cbic.201600244

17. Medhurst AD, Jennings CA, Robbins MJ, Davis RP, Ellis C, Winborn KY, et al. Pharmacological and immunohistochemical characterization of the APJ receptor and its endogenous ligand apelin. J Neurochem (2003) 84:1162-72. doi:10.1046/j.1471-4159.2003.01587.x

18. Iturrioz X, Gerbier R, Leroux V, Alvear-Perez R, Maigret B, Llorens-Cortes C. By interacting with the C-terminal Phe of apelin, Phe(255) and $\operatorname{Trp}(259)$ in helix VI of the apelin receptor are critical for internalization. J Biol Chem (2010) 285:32627-37. doi:10.1074/jbc.M110.127167

19. GerbierR,Leroux V,Couvineau P,Alvear-PerezR, MaigretB,Llorens-Cortes C, et al. New structural insights into the apelin receptor: identification of key residues for apelin binding. FASEB J (2015) 29:314-22. doi:10.1096/ fj. 14-256339

20. El Messari S, Iturrioz X, Fassot C, De Mota N, Roesch D, Llorens-Cortes C. Functional dissociation of apelin receptor signaling and endocytosis: implications for the effects of apelin on arterial blood pressure. J Neurochem (2004) 90:1290-301. doi:10.1111/j.1471-4159.2004.02591.x

21. Masri B, Morin N, Pedebernade L, Knibiehler B, Audigier Y. The apelin receptor is coupled to $\mathrm{Gi} 1$ or Gi2 protein and is differentially desensitized by apelin fragments. J Biol Chem (2006) 281:18317-26. doi:10.1074/jbc.M600606200

22. Bai B, Tang J, Liu H, Chen J, Li Y, Song W. Apelin-13 induces ERK1/2 but not p38 MAPK activation through coupling of the human apelin receptor to the Gi2 pathway. Acta Biochim Biophys Sin (Shanghai) (2008) 40:311-8. doi:10.1111/j.1745-7270.2008.00403.x

23. Choe W, Albright A, Sulcove J, Jaffer S, Hesselgesser J, Lavi E, et al. Functional expression of the seven-transmembrane HIV-1 co-receptor APJ in neural cells. J Neurovirol (2000) 6(Suppl 1):S61-9.

24. Zhou N, Fan X, Mukhtar M, Fang J, Patel CA, DuBois GC, et al. Cell-cell fusion and internalization of the CNS-based, HIV-1 co-receptor, APJ. Virology (2003) 307:22-36. doi:10.1016/S0042-6822(02)00021-1

25. Zhou N, Zhang X, Fan X, Argyris E, Fang J, Acheampong E, et al. The $\mathrm{N}$-terminal domain of APJ, a CNS-based coreceptor for HIV-1, is essential for its receptor function and coreceptor activity. Virology (2003) 317:84-94 doi:10.1016/j.virol.2003.08.026

26. Hus-Citharel A, Bouby N, Frugière A, Bodineau L, Gasc J-M, Llorens-Cortes C. Effect of apelin on glomerular hemodynamic function in the rat kidney. Kidney Int (2008) 74:486-94. doi:10.1038/ki.2008.199

27. Szokodi I, Tavi P, Földes G, Voutilainen-Myllylä S, Ilves M, Tokola H, et al. Apelin, the novel endogenous ligand of the orphan receptor APJ, regulates cardiac contractility. Circ Res (2002) 91:434-40. doi:10.1161/01. RES.0000033522.37861.69

28. Langelaan DN, Bebbington EM, Reddy T, Rainey JK. Structural insight into G-protein coupled receptor binding by apelin. Biochemistry (2009) 48:537-48. doi:10.1021/bi801864b

29. Masri B, Lahlou H, Mazarguil H, Knibiehler B, Audigier Y. Apelin (65-77) activates extracellular signal-regulated kinases via a PTX-sensitive G protein. Biochem Biophys Res Commun (2002) 290:539-45. doi:10.1006/ bbrc. 2001.6230

30. Eyries M, Siegfried G, Ciumas M, Montagne K, Agrapart M, Lebrin F, et al. Hypoxia-induced apelin expression regulates endothelial cell proliferation and regenerative angiogenesis. Circ Res (2008) 103:432-40. doi:10.1161/ CIRCRESAHA.108.179333

31. D'Aniello C, Lonardo E, Iaconis S, Guardiola O, Liguoro AM, Liguori GL, et al. G protein-coupled receptor APJ and its ligand apelin act downstream of Cripto to specify embryonic stem cells toward the cardiac lineage through extracellular signal-regulated kinase/p70S6 kinase signaling pathway. Circ Res (2009) 105:231-8. doi:10.1161/CIRCRESAHA.109.201186

32. Reaux A, De Mota N, Skultetyova I, Lenkei Z, El Messari S, Gallatz K, et al. Physiological role of a novel neuropeptide, apelin, and its receptor in the rat brain. J Neurochem (2001) 77:1085-96. doi:10.1046/j.1471-4159.2001 00320.x

33. Gerbier R, Alvear-Perez R, Margathe J-F, Flahault A, Couvineau P, Gao J, et al. Development of original metabolically-stable apelin-17 analogs with diuretic and cardiovascular effects. FASEB J (2017) 31(2):687-700. doi:10.1096/ f. $201600784 \mathrm{R}$

34. Ceraudo E, Galanth C, Carpentier E, Banegas-Font I, Schonegge A-M, Alvear-Perez $\mathrm{R}$, et al. Biased signaling favoring gi over $\beta$-arrestin promoted by an apelin fragment lacking the C-terminal phenylalanine. J Biol Chem (2014) 289:24599-610. doi:10.1074/jbc.M113.541698

35. Lee DK, Saldivia VR, Nguyen T, Cheng R, George SR, O'Dowd BF. Modification of the terminal residue of apelin-13 antagonizes its hypotensive action. Endocrinology (2005) 146:231-6. doi:10.1210/en.2004-0359

36. Lee DK, Ferguson SSG, George SR, O'Dowd BF. The fate of the internalized apelin receptor is determined by different isoforms of apelin mediating 
differential interaction with beta-arrestin. Biochem Biophys Res Commun (2010) 395:185-9. doi:10.1016/j.bbrc.2010.03.151

37. Chun HJ, Ali ZA, Kojima Y, Kundu RK, Sheikh AY, Agrawal R, et al. Apelin signaling antagonizes Ang II effects in mouse models of atherosclerosis. J Clin Invest (2008) 118:3343-54. doi:10.1172/JCI34871

38. Sun X, Iida S, Yoshikawa A, Senbonmatsu R, Imanaka K, Maruyama K, et al. Non-activated APJ suppresses the angiotensin II type 1 receptor, whereas apelin-activated APJ acts conversely. Hypertens Res (2011) 34:701-6. doi:10.1038/hr.2011.19

39. Siddiquee K, Hampton J, McAnally D, May L, Smith L. The apelin receptor inhibits the angiotensin II type 1 receptor via allosteric trans-inhibition. $\mathrm{Br}$ J Pharmacol (2013) 168:1104-17. doi:10.1111/j.1476-5381.2012.02192.x

40. Li Y, Chen J, Bai B, Du H, Liu Y, Liu H. Heterodimerization of human apelin and kappa opioid receptors: roles in signal transduction. Cell Signal (2012) 24:991-1001. doi:10.1016/j.cellsig.2011.12.012

41. Bai B, Liu L, Zhang N, Wang C, Jiang Y, Chen J. Heterodimerization of human apelin and bradykinin 1 receptors: novel signal transduction characteristics. Cell Signal (2014) 26:1549-59. doi:10.1016/j.cellsig.2014.03.022

42. Murza A, Belleville K, Longpré J-M, Sarret P, Marsault É. Stability and degradation patterns of chemically modified analogs of apelin-13 in plasma and cerebrospinal fluid. Biopolymers (2014) 102:297-303. doi:10.1002/bip.22498

43. Japp AG, Cruden NL, Barnes G, van Gemeren N, Mathews J, Adamson J, et al. Acute cardiovascular effects of apelin in humans: potential role in patients with chronic heart failure. Circulation (2010) 121:1818-27. doi:10.1161/ CIRCULATIONAHA.109.911339

44. Jia ZQ, Hou L, Leger A, Wu I, Kudej AB, Stefano J, et al. Cardiovascular effects of a PEGylated apelin. Peptides (2012) 38:181-8. doi:10.1016/j. peptides.2012.09.003

45. Galon-Tilleman H, Yang H, Bednarek MA, Spurlock SM, Paavola KJ, Ko B, et al. Apelin-36 modulates blood glucose and body weight independently of canonical APJ receptor signaling. J Biol Chem (2017) 292:1925-33. doi:10.1074/jbc.M116.748103

46. Juhl C, Els-Heindl S, Schönauer R, Redlich G, Haaf E, Wunder F, et al. Development of potent and metabolically stable APJ ligands with high therapeutic potential. ChemMedChem (2016) 11(21):2378-84. doi:10.1002/ cmdc. 201600307

47. Sidorova MV, Az'muko AA, Pal'keeva ME, Molokoedov AS, Bushuev VN, Dvoriantsev SN, et al. [Synthesis and cardioprotective properties of apelin-12 and its structural analogs]. Bioorg Khim (2012) 38:40-51. doi:10.1134/ S1068162012010177

48. Murza A, Parent A, Besserer-Offroy E, Tremblay H, Karadereye F, Beaudet N, et al. Elucidation of the structure-activity relationships of apelin: influence of unnatural amino acids on binding, signaling, and plasma stability. ChemMedChem (2012) 7:318-25. doi:10.1002/cmdc.201100492

49. Hamada J, Kimura J, Ishida J, Kohda T, Morishita S, Ichihara S, et al. Evaluation of novel cyclic analogues of apelin. Int J Mol Med (2008) 22:547-52. doi:10.3892/ijmm_00000054

50. Brame AL, Maguire JJ, Yang P, Dyson A, Torella R, Cheriyan J, et al. Design, characterization, and first-in-human study of the vascular actions of a novel biased apelin receptor agonist. Hypertension (2015) 65:834-40. doi:10.1161/ HYPERTENSIONAHA.114.05099

51. Murza A, Sainsily X, Côté J, Bruneau-Cossette L, Besserer-Offroy É, Longpré J-M, et al. Structure-activity relationship of novel macrocyclic biased apelin receptor agonists. Org Biomol Chem (2017) 15:449-58. doi:10.1039/ c6ob02247b

52. Fosgerau K, Hoffmann T. Peptide therapeutics: current status and future directions. Drug Discov Today (2015) 20:122-8. doi:10.1016/j.drudis.2014.10.003

53. Murza A, Besserer-Offroy É, Côté J, Bérubé P, Longpré J-M, Dumaine R, et al. C-Terminal modifications of apelin-13 significantly change ligand binding, receptor signaling, and hypotensive action. J Med Chem (2015) 58:2431-40. doi:10.1021/jm501916k

54. Fan X, Zhou N, Zhang X, Mukhtar M, Lu Z, Fang J, et al. Structural and functional study of the apelin-13 peptide, an endogenous ligand of the HIV-1 coreceptor, APJ. Biochemistry (2003) 42:10163-8. doi:10.1021/ bi030049s

55. Pope GR, Roberts EM, Lolait SJ, O'Carroll A-M. Central and peripheral apelin receptor distribution in the mouse: species differences with rat. Peptides (2012) 33:139-48. doi:10.1016/j.peptides.2011.12.005
56. Reaux A, Gallatz K, Palkovits M, Llorens-Cortes C. Distribution of apelin-synthesizing neurons in the adult rat brain. Neuroscience (2002) 113:653-62. doi:10.1016/S0306-4522(02)00192-6

57. Brailoiu GC, Dun SL, Yang J, Ohsawa M, Chang JK, Dun NJ. Apelinimmunoreactivity in the rat hypothalamus and pituitary. Neurosci Lett (2002) 327:193-7. doi:10.1016/S0304-3940(02)00411-1

58. Reaux A, Morinville A, Burlet A, Llorens-Cortes C, Beaudet A. Dehydrationinduced cross-regulation of apelin and vasopressin immunoreactivity levels in magnocellular hypothalamic neurons. Endocrinology (2004) 145:4392-400. doi:10.1210/en.2004-0384

59. Bodineau L, Taveau C, Lê Quan Sang H-H, Osterstock G, Queguiner I, Moos F, et al. Data supporting a new physiological role for brain apelin in the regulation of hypothalamic oxytocin neurons in lactating rats. Endocrinology (2011) 152:3492-503. doi:10.1210/en.2011-0206

60. Buggy J, Fink GD, Johnson AK, Brody MJ. Prevention of the development of renal hypertension by anteroventral third ventricular tissue lesions. Circ Res (1977) 40:I110-7.

61. Johnson AK, Cunningham JT, Thunhorst RL. Integrative role of the lamina terminalis in the regulation of cardiovascular and body fluid homeostasis. Clin Exp Pharmacol Physiol (1996) 23:183-91. doi:10.1111/j.1440-1681.1996. tb02594.x

62. O'Carroll A-M, Lolait SJ. Regulation of rat APJ receptor messenger ribonucleic acid expression in magnocellular neurones of the paraventricular and supraopric nuclei by osmotic stimuli. J Neuroendocrinol (2003) 15:661-6. doi:10.1046/j.1365-2826.2003.01044.x

63. Hurbin A, Boissin-Agasse L, Orcel H, Rabié A, Joux N, Desarménien MG, et al. The V1a and V1b, but not V2, vasopressin receptor genes are expressed in the supraoptic nucleus of the rat hypothalamus, and the transcripts are essentially colocalized in the vasopressinergic magnocellular neurons. Endocrinology (1998) 139:4701-7. doi:10.1210/endo.139.11.6320

64. Kleinz MJ, Skepper JN, Davenport AP. Immunocytochemical localisation of the apelin receptor, APJ, to human cardiomyocytes, vascular smooth muscle and endothelial cells. Regul Pept (2005) 126:233-40. doi:10.1016/j. regpep.2004.10.019

65. Ostrowski NL, Lolait SJ, Bradley DJ, O'Carroll AM, Brownstein MJ, Young WS. Distribution of V1a and V2 vasopressin receptor messenger ribonucleic acids in rat liver, kidney, pituitary and brain. Endocrinology (1992) 131:533-5. doi:10.1210/endo.131.1.1535312

66. Brownstein MJ, Russell JT, Gainer H. Synthesis, transport, and release of posterior pituitary hormones. Science (1980) 207:373-8. doi:10.1126/ science.6153132

67. Manning M, Lowbridge J, Haldar J, Sawyer WH. Design of neurohypophyseal peptides that exhibit selective agonistic and antagonistic properties. Fed Proc (1977) 36:1848-52.

68. ZiniS, Fournie-Zaluski MC, ChauvelE, Roques BP, CorvolP, Llorens-CortesC. Identification of metabolic pathways of brain angiotensin II and III using specific aminopeptidase inhibitors: predominant role of angiotensin III in the control of vasopressin release. Proc Natl Acad Sci U S A (1996) 93:11968-73. doi:10.1073/pnas.93.21.11968

69. Gouzènes L, Desarménien MG, Hussy N, Richard P, Moos FC. Vasopressin regularizes the phasic firing pattern of rat hypothalamic magnocellular vasopressin neurons. J Neurosci (1998) 18:1879-85.

70. Ludwig M. Dendritic release of vasopressin and oxytocin. J Neuroendocrinol (1998) 10:881-95. doi:10.1046/j.1365-2826.1998.00279.x

71. Poulain DA, Wakerley JB, Dyball RE. Electrophysiological differentiation of oxytocin- and vasopressin-secreting neurones. Proc R Soc Lond B Biol Sci (1977) 196:367-84. doi:10.1098/rspb.1977.0046

72. Gimpl G, Fahrenholz F. The oxytocin receptor system: structure, function, and regulation. Physiol Rev (2001) 81:629-83.

73. Hogarty DC, Speakman EA, Puig V, Phillips MI. The role of angiotensin, AT1 and AT2 receptors in the pressor, drinking and vasopressin responses to central angiotensin. Brain Res (1992) 586:289-94. doi:10.1016/0006-8993 (92)91638-U

74. Kadekaro M,Summy-Long JY, Freeman S, HarrisJS, Terrell ML, EisenbergHM. Cerebral metabolic responses and vasopressin and oxytocin secretions during progressive water deprivation in rats. Am J Physiol (1992) 262:R310-7.

75. Nielsen S, Chou CL, Marples D, Christensen EI, Kishore BK, Knepper MA. Vasopressin increases water permeability of kidney collecting duct by 
inducing translocation of aquaporin-CD water channels to plasma membrane. Proc Natl Acad Sci U S A (1995) 92:1013-7. doi:10.1073/pnas.92.4.1013

76. Sands JM, Naruse M, Baum M, Jo I, Hebert SC, Brown EM, et al. Apical extracellular calcium/polyvalent cation-sensing receptor regulates vasopressin-elicited water permeability in rat kidney inner medullary collecting duct. J Clin Invest (1997) 99:1399-405. doi:10.1172/JCI119299

77. Hus-Citharel A, Bodineau L, Frugière A, Joubert F, Bouby N, Llorens-Cortes C. Apelin Counteracts Vasopressin-Induced Water Reabsorption via Cross Talk Between Apelin and Vasopressin Receptor Signaling Pathways in the Rat Collecting Duct. Endocrinology (2014) 155:4483-93. doi:10.1210/en. 2014-1257

78. Murza A, Sainsily X, Coquerel D, Côté J, Marx P, Besserer-Offroy É, et al. Discovery and structure-activity relationship of a bioactive fragment of ELABELA that modulates vascular and cardiac functions. $\mathrm{J} \mathrm{Med} \mathrm{Chem}$ (2016) 59:2962-72. doi:10.1021/acs.jmedchem.5b01549

79. Deng C, Chen H, Yang N, Feng Y, Hsueh AJW. Apela regulates fluid homeostasis by binding to the APJ receptor to activate Gi signaling. J Biol Chem (2015) 290:18261-8. doi:10.1074/jbc.M115.648238

80. Roberts EM, Newson MJF, Pope GR, Landgraf R, Lolait SJ, O’Carroll A-M. Abnormal fluid homeostasis in apelin receptor knockout mice. J Endocrinol (2009) 202:453-62. doi:10.1677/JOE-09-0134

81. Roberts EM, Pope GR, Newson MJF, Landgraf R, Lolait SJ, O'Carroll A-M. Stimulus-specific neuroendocrine responses to osmotic challenges in apelin receptor knockout mice. J Neuroendocrinol (2010) 22:301-8. doi:10.1111/ j.1365-2826.2010.01968.x

82. Tang C, Zelenak C, Völkl J, Eichenmüller M, Regel I, Fröhlich H, et al. Hydration-sensitive gene expression in brain. Cell Physiol Biochem (2011) 27:757-68. doi:10.1159/000330084

83. Zingg HH, Lefebvre D, Almazan G. Regulation of vasopressin gene expression in rat hypothalamic neurons. Response to osmotic stimulation. J Biol Chem (1986) 261:12956-9.

84. Jéquier E, Constant F. Water as an essential nutrient: the physiological basis of hydration. Eur J Clin Nutr (2010) 64:115-23. doi:10.1038/ejcn.2009.111

85. Phillips PA, Rolls BJ, Ledingham JG, Forsling ML, Morton JJ, Crowe MJ, et al. Reduced thirst after water deprivation in healthy elderly men. N Engl J Med (1984) 311:753-9. doi:10.1056/NEJM198409203111202

86. Fliers E, Swaab DF, Pool CW, Verwer RW. The vasopressin and oxytocin neurons in the human supraoptic and paraventricular nucleus; changes with aging and in senile dementia. Brain Res (1985) 342:45-53. doi:10.1016/0006-8993(85)91351-4

87. Hoogendijk JE, Fliers E, Swaab DF, Verwer RW. Activation of vasopressin neurons in the human supraoptic and paraventricular nucleus in senescence and senile dementia. JNeurol Sci (1985) 69:291-9. doi:10.1016/ 0022-510X(85)90141-8

88. Lucassen PJ, Salehi A, Pool CW, Gonatas NK, Swaab DF. Activation of vasopressin neurons in aging and Alzheimer's disease. J Neuroendocrinol (1994) 6:673-9. doi:10.1111/j.1365-2826.1994.tb00634.x

89. Palin K, Moreau ML, Orcel H, Duvoid-Guillou A, Rabié A, Kelley KW, et al. Age-impaired fluid homeostasis depends on the balance of IL-6/IGF-I in the rat supraoptic nuclei. Neurobiol Aging (2009) 30:1677-92. doi:10.1016/j. neurobiolaging.2007.12.006

90. Fliers E, Swaab DF. Activation of vasopressinergic and oxytocinergic neurons during aging in the Wistar rat. Peptides (1983) 4:165-70. doi:10.1016/ 0196-9781(83)90108-0

91. Terwel D, ten Haaf JA, Markerink M, Jolles J. Changes in plasma vasopressin concentration and plasma osmolality in relation to age and time of day in the male Wistar rat. Acta Endocrinol (1992) 126:357-62.

92. Sladek CD, Olschowka JA. Dehydration induces Fos, but not increased vasopressin mRNA in the supraoptic nucleus of aged rats. Brain Res (1994) 652:207-15. doi:10.1016/0006-8993(94)90229-1

93. Palin K, Moreau ML, Sauvant J, Orcel H, Nadjar A, Duvoid-Guillou A, et al. Interleukin-6 activates arginine vasopressin neurons in the supraoptic nucleus during immune challenge in rats. Am J Physiol Endocrinol Metab (2009) 296:E1289-99. doi:10.1152/ajpendo.90489.2008

94. Sauvant J, Delpech J-C, Palin K, De Mota N, Dudit J, Aubert A, et al. Mechanisms involved in dual vasopressin/apelin neuron dysfunction during aging. PLoS One (2014) 9:e87421. doi:10.1371/journal.pone.0087421

95. Morgenthaler NG, Struck J, Jochberger S, Dünser MW. Copeptin: clinical use of a new biomarker. Trends Endocrinol Metab (2008) 19:43-9. doi:10.1016/j. tem.2007.11.001

96. Balanescu S, Kopp P, Gaskill MB, Morgenthaler NG, Schindler C, RutishauserJ. Correlation of plasma copeptin and vasopressin concentrations in hypo-, iso-, and hyperosmolar states. J Clin Endocrinol Metab (2011) 96:1046-52. doi:10.1210/jc.2010-2499

97. Fenske W, Störk S, Blechschmidt A, Maier SGK, Morgenthaler NG, Allolio B. Copeptin in the differential diagnosis of hyponatremia. JClin Endocrinol Metab (2009) 94:123-9. doi:10.1210/jc.2008-1426

98. Ellison DH, Berl T. Clinical practice. The syndrome of inappropriate antidiuresis. N Engl J Med (2007) 356:2064-72. doi:10.1056/NEJMcp066837

99. Fenske WK, Christ-Crain M, Hörning A, Simet J, Szinnai G, Fassnacht M, et al. A copeptin-based classification of the osmoregulatory defects in the syndrome of inappropriate antidiuresis. J Am Soc Nephrol (2014) 25:2376-83. doi:10.1681/ASN.2013080895

100. Blanchard A, Steichen O, De Mota N, Curis E, Gauci C, Frank M, et al. An abnormal apelin/vasopressin balance may contribute to water retention in patients with the syndrome of inappropriate antidiuretic hormone (SIADH) and heart failure. J Clin Endocrinol Metab (2013) 98:2084-9. doi:10.1210/ jc.2012-3794

101. Urso C, Brucculeri S, Caimi G. Acid-base and electrolyte abnormalities in heart failure: pathophysiology and implications. Heart Fail Rev (2015) 20:493-503. doi:10.1007/s10741-015-9482-y

102. Sica DA. Hyponatremia and heart failure - pathophysiology and implications. Congest Heart Fail (2005) 11:274-7. doi:10.1111/j.1527-5299.2005. 04180.x

103. Goldsmith SR, Francis GS, Cowley AW. Arginine vasopressin and the renal response to water loading in congestive heart failure. Am J Cardiol (1986) 58:295-9. doi:10.1016/0002-9149(86)90065-2

104. Chin MH, Goldman L. Correlates of major complications or death in patients admitted to the hospital with congestive heart failure. Arch Intern Med (1996) 156:1814-20. doi:10.1001/archinte.156.16.1814

105. Christ-Crain M, Fenske W. Copeptin in the diagnosis of vasopressin-dependent disorders of fluid homeostasis. Nat Rev Endocrinol (2016) 12:168-76. doi:10.1038/nrendo.2015.224

106. Timper K, Fenske W, Kühn F, Frech N, Arici B, Rutishauser J, et al. Diagnostic accuracy of copeptin in the differential diagnosis of the polyuria-polydipsia syndrome: a prospective multicenter study. J Clin Endocrinol Metab (2015) 100:2268-74. doi:10.1210/jc.2014-4507

107. Urwyler SA, Timper K, Fenske W, de Mota N, Blanchard A, Kühn F, et al. Plasma apelin concentrations in patients with polyuria-polydipsia syndrome. J Clin Endocrinol Metab (2016) 101(5):1917-23. doi:10.1210/jc. 2016-1158

Conflict of Interest Statement: The authors declare that the research was conducted in the absence of any commercial or financial relationships that could be construed as a potential conflict of interest.

Copyright (๑) 2017 Flahault, Couvineau, Alvear-Perez, Iturrioz and Llorens-Cortes. This is an open-access article distributed under the terms of the Creative Commons Attribution License (CC BY). The use, distribution or reproduction in other forums is permitted, provided the original author(s) or licensor are credited and that the original publication in this journal is cited, in accordance with accepted academic practice. No use, distribution or reproduction is permitted which does not comply with these terms. 